\title{
Sensibilidades legales y usos alternativos del derecho. El encierro ganadero comunitario "El Rejunte" (Figueroa, Santiago del Estero)
}

\author{
Legal sensibilities and alternative uses of law. The community livestock enclosure \\ "El Rejunte" (Figueroa, Santiago del Estero)
}

\author{
Claudia Yesica Fonzo Bolañez \\ jessica_bzp@hotmail.com \\ Instituto Interamericano para el Desarrollo Económico \\ y Social - Facultad de Humanidades, Ciencias Sociales \\ y de la Salud - Universidad Nacional de Santiago del \\ Estero - CONICET, Argentina
}

Recepción: 14 Febrero 2020

Aprobación: 20 Julio 2020

Publicación: 02 Agosto 2020

Cita sugerida: Fonzo Bolañez, C. Y. (2020).

Sensibilidades legales y usos alternativos del derecho. El encierro ganadero comunitario "El Rejunte” (Figueroa, Santiago del Estero). Cuestiones de Sociología, 23, e106. https://doi.org/10.24215/23468904e106
Resumen: El objetivo de este artículo es presentar algunas reflexiones construidas a partir del trabajo de campo que realicé en el encierro comunitario "El Rejunte", ubicado en Figueroa, Santiago del Estero, Argentina. En particular, lo comprendido en relación a las prácticas de gestión de conflictos rurales y a las sensibilidades legales respecto al derecho de propiedad, desplegadas por campesinos y agentes estatales involucrados en su conformación. Al etnografiar pra\#cticas y sentidos agenciados en torno al uso del derecho estatal, pude advertir co\#mo estos actores (re)producen y (re)definen una política pública, las legalidades alrededor del derecho de propiedad, los sentidos y usos del territorio. Asimismo, ciertos límites en los usos alternativos de la legalidad, en cuanto no todos los grupos y personas tienen las mismas posibilidades al momento de emplearla; como a la internalización de las formas dominantes de representación del derecho en la propia conformación de la subjetividad. Es decir, pensar a estos procesos como ambiguos e inacabados, los derechos como construcciones sociales que viabilizan formas de dominación, pero también, emancipación.

Palabras clave: Usos alternativos del derecho, Sensibilidades legales, Derecho de propiedad, Políticas públicas, Encierro comunitario ganadero.

Abstract: The objective of this article is to present some reflections constructed from the field work that I carried out in the community enclosure "El Rejunte", located in Figueroa, Santiago del Estero, Argentina. In particular, what is understood in relation to rural conflict management practices and legal sensitivities regarding property rights, deployed by peasants and state agents involved in its formation. By ethnographing practices and senses organized around the use of state law, I could see how these actors (re)produce and (re)define a public policy, the legalities around property rights, the senses and uses of the territory. Likewise, certain limits on the alternative uses of legality, insofar as not all groups and individuals have the same possibilities when using it; as to the internalization of the dominant forms of representation of law in the conformation of subjectivity itself. That is, think of these processes as ambiguous 
and unfinished; rights as social constructions, which enable forms of domination, but also, emancipation.

Keywords: Alternative uses of law, Legal sensitivities, Property rights, Public politics, Community livestock confinement.

\section{INTRODUCCIÓN}

Como estrategia para afianzar su condición de poseedores y poder adquirir la titularidad de dominio algunas comunidades campesinas emplazadas en los departamentos Figueroa y Moreno de la provincia de Santiago del Estero, Argentina, vinculadas con técnicos de terreno del ex Programa Social Agropecuario (PSA), posteriormente, Secretaría de Agricultura Familiar de la Nación de la Delegación de Santiago del Estero (SAF), gestaron los emprendimientos comunitarios de cría, manejo, engorde y venta de ganado bovino por el año 2006 (Villalba, Gómez Herrera, Concha Merlo y Ferreyra, 2016; de Dios y Ferreyra, 2011).

Estos emprendimientos pusieron en marcha proyectos de cercamiento o alambrado de tierras comunales, mejoras en la calidad del rodeo bovino, implantación de pasturas y adquisición u optimización de instalaciones ganaderas, los cuales fueron financiados por diversos programas de desarrollo rural de la nación e implicaron un cambio significativo de las prácticas productivas tradicionales de los pequeños productores y/o campesinos. Los encierros ganaderos son una iniciativa que surge del vínculo entre campesinos y técnicos, y que se concretan en su mayoría en contextos de conflictos por la tierra. En la actualidad existen diecinueve encierros en los departamentos mencionados, en distintos estados de avance y desarrollo.

Si bien dichas experiencias se diseñaron y constituyeron con una finalidad primordialmente productiva, de potenciar el aprovechamiento de los recursos disponibles por las familias campesinas, con el tiempo y a través de las relaciones y dinámicas entre campesinos y técnicos en los diferentes territorios fueron adquiriendo nuevos matices y finalidades. A partir de las circunstancias a las que se enfrentaron los mismos, estos emprendimientos se reorientaron a la atención de la problemática de la tenencia precaria de la tierra, resignificando y reorientando sus objetivos iniciales.

En los inicios de algunos de estos proyectos se aprovechó la dinámica asociativa que emergió de las distintas instancias de lucha o resistencia en defensa de la tierra, que fueron desplegando las comunidades campesinas. Esta experiencia asociativa y organizacional predispuso favorablemente a los productores para plantearse nuevos objetivos vinculados al manejo ganadero. La defensa de las áreas de pastoreo comunitario extensivo es el punto más conflictivo de la lucha por la tierra y a la vez significó una oportunidad y motivación para que los productores plantearan la construcción de alambrados perimetrales y la introducción de otras mejoras en infraestructura, todas las cuales resultarían útiles para un manejo diferente de la hacienda, pero al mismo tiempo constitutivas de los llamados actos posesorios.

Es a partir de la relación dialéctica entre técnicos-campesinos, que surge y se despliega una estrategia de defensa de la tierra basada en producir-hacer posesión. Es decir, se sustenta en las disposiciones del derecho posesorio pregonado en el discurso y prácticas de campesinos y organizaciones que asumen su representación en las luchas por la tierra, pero se desarrolla a través de propuestas técnico-productivas promovidas por la institucionalidad pública. Desde los márgenes, diálogos, articulación y conflictos con otros mediadores sociales -como los distintos agentes estatales intervinientes-, y de las dinámicas de los territorios, los campesinos construyen emergencias, alternativas y posibles respuestas a los conflictos por la tierra, en un contexto legal y político que no ofrece soluciones de fondo a la inseguridad jurídica y a la precariedad de la tenencia de la tierra. Construyen los encierros ganaderos para hacer posesión y, por ende, resignifican el derecho estatal vigente; construyen posesión produciendo, organizándose, y, por ello, reconfiguran las políticas públicas. 
El objetivo de este artículo es presentar algunas reflexiones construidas a partir del trabajo de campo etnográfico que realicé durante el año 2019 en los encierros comunitarios ganaderos ubicados en los departamentos Figueroa y Moreno, de Santiago del Estero. En particular, lo comprendido en relación a las prácticas de gestión de conflictos rurales por la tenencia de la tierra y a las sensibilidades legales respecto al derecho de propiedad y posesión, desplegadas por campesinos y agentes estatales involucrados en la conformación del encierro ganadero comunitario "El Rejunte". Para ello analizo, desde una perspectiva etnográfica, las experiencias y relaciones de pobladores rurales, abogado, te\#cnicos y funcionarios de la Subsecretari\#a de Agricultura Familiar implicados en la conformacio\#n del encierro.

\section{Propiedad en cuestión: Génesis de “El Rejunte” desde las narrativas de los CONFLICTOS}

El encierro comunitario Cayaschi o "El Rejunte", como sus integrantes lo llaman, surge por el año 2007, en el marco de la lucha por la tierra, la concientización de sus derechos y la organización colectiva de los campesinos y pequeños productores de la región. Así, quien fue el impulsor principal en su conformación, un maestro de una escuela de la zona, presidente de la DUFINOC (Delegados Unidos de Figueroa Norte y Once Comunidades) ${ }^{1}$ por aquellos años y uno de los primeros miembros de la Mesa de Tierras de Figueroa, ${ }^{2}$ me comentó al respecto: "En nuestro caso, nuestra lucha viene del nacimiento de la DUFINOC desde el 92, antes de empezar a reunirnos con ese nombre y ahí ya nos planteábamos, muchachos nosotros tenemos que cerrar nuestra posesión ${ }^{3}(. .$.$) ".$

Sus palabras develan que las acciones de resistencia y defensa colectiva de la tierra son previas a la conformación del grupo productivo. A pesar de estas y de la participación en organizaciones campesinas para preservar las tierras en disputa, no se logró una solución que diera garantías para evitar en un futuro potenciales acciones de desalojo. Esto podría explicar en parte la predisposición de los campesinos de la zona hacia la propuesta de los técnicos de terreno de construir el encierro comunitario ganadero.

Los integrantes del encierro sostienen que a partir de reuniones previas con vecinos de otros parajes del departamento y un técnico de la SAF obtuvieron información de los derechos posesorios sobre la tierra. Asimismo, en estos espacios compartían experiencias con quienes se encontraban resistiendo a desalojos o atravesando experiencias de ejecución de políticas públicas análogas. El nacimiento, como mantenimiento del encierro se realizó a partir de decisiones que fueron consensuadas y compartidas en reuniones periódicas por sus miembros, independientemente de la presencia y acompañamiento del equipo técnico. A partir de las reuniones se definen y refundan rutinas, estrategias y sentidos de luchas por las tierras comunales.

No obstante, el proceso de fijar los límites del encierro implicó un proceso de consensos y desacuerdos, como de una historia alrededor de la propiedad atravesada por disputas en torno a la titularidad y los límites de esta. Esto se pone en evidencia en el siguiente relato:

Así hemos empezado a hacer los deslindes, al principio los kilómetros los hacíamos como queríamos, mal hecho por supuesto, después nos hemos concentrado en diseñar mejor con $2 \mathrm{~km}$, por un lado, y por el otro, reunirnos con Santa Catalina [un paraje contiguo] para hacer el deslinde de ambas comunidades a medias. Y nosotros nos llamamos Cayaschi (El Rejunte), pero esto en el año 1940 para atrás se llamaba "Mistol Rodeo". Ha venido un turco llamado Abdo y ganó en un remate la mitad, dividió y le vendió a la bisabuela de este que aquí está. Le vendió 2000 ha, que a su vez lo terminó hipotecando, un Desiderio Taboada (...) terminó siendo dueño de aquí a $80 \mathrm{~km}$. De esa explotación, le vende 1000 ha a la bisabuela de él [señalando a un compañero nuevamente] y dentro de esas 1000, vende 5 lotes de 25 ha, que sería este lote, el paraje San Francisco. De estas 25 ha tengo la escritura de mi abuelo del año 1917(...) (Entrevista a socio fundador y productor de "El Rejunte", mayo de 2019).

Se observan ciertas contradicciones respecto a la categoría de "dueño" o "propietario" en términos del derecho estatal, ya que por un lado reconoce y por otro cuestiona a esta, es decir, a quienes son titulares 
registrales. Ello torna inteligible porque el problema de la inseguridad jurídica subyace y persiste en Santiago del Estero.

En un diálogo entablado con otro de los integrantes del encierro, actual vicepresidente de la DUFINOC, maestro en Bandera Bajada (ciudad más importante del departamento), nos aclara que, desde niño en la escuela de Santa Ana, siempre había escuchado a esta persona, quien fue su maestro y padrino, decir: "Tenemos que cerrar y producir esto (...)", y que en su adultez tomó conocimiento y consciencia que su maestro necesitaba del apoyo de los vecinos para llevar a cabo su idea. Entonces junto a él, el hermano de este, y otros campesinos comenzaron a hablar a las familias vecinas y a reunirse.

El primer día que nos reunimos éramos 4 nada más. Luego cuando comenzamos a deslindar con el hacha, ahí mis vecinos toman consciencia, se dan cuenta y se incorporan. Hemos deslindado todo a hacha y machete, como $30 \mathrm{~km}$, a picadas anchas, a todo pulmón (Entrevista a campesino miembro de "El Rejunte", junio 2019).

Sus palabras permiten entrever la capacidad de algunos de los integrantes del encierro de reflexionar y "tomar consciencia" sobre la necesidad de administrar comunitariamente los recursos, lo que implica un trabajo de autodisciplinamiento orientado a modificar ciertas prácticas y a afrontar posibles tensiones intracomunitarias. Son los mismos actores, en la coyuntura de la creación del encierro, los que comienzan a percibir los recursos como escasos, y a pensar que cambios en sus prácticas productivas y los modos de apropiarse del medio natural podrían ser útiles para evitar futuros desalojos. Al interior de la comunidad se planteó la necesidad de ordenar el uso del espacio, regular el aprovechamiento mancomún del monte con miras a preservarlo y defender sus derechos a la propiedad de la tierra.

Inmediatamente, en dicha entrevista expresa que el alambre fue comprado en los inicios por los propios vecinos que podían colaborar, también que la comunidad de San Felipe les prestó unos cuantos rollos de alambre (que devolvieron con posterioridad con un préstamo de la DUFINOC y un rollo de más en concepto de intereses), luego, que a través de un sistema de microcréditos de $\$ 3.000$ (tres mil pesos) por familia, la DUFINOC financiaba el alambrado y en los últimos 5 años fue la SAF quien otorgó los fondos para tales fines. ${ }^{4}$

Más adelante, este campesino miembro del encierro señala: "Luego cuando deslindamos surgió el problema. En el año 2011 surge el conflicto; vino una señora diciendo que era la hija heredera de don Abdo Jorge, quien, decían, era el dueño de las tierras de la época del obraje”. Ante ello, los campesinos afectados, muchos integrantes de la Mesa de Tierra de Figueroa y la DUFINOC, tomaron contacto con los técnicos del ex PSA. De la interacción entre estos actores surgió la iniciativa de organizarse en un grupo productor ${ }^{5}$ con el fin de construir "potreros", puesto que era un modo estratégico de impedir el despojo de las tierras y afianzar la posesión ante un posible litigio.

En aquella entrevista con el impulsor del encierro, comenta respecto al conflicto:

Volviendo a nuestra historia de grupo en el 2007 al ver que se forma esa Mesa de Tierras en el departamento Figueroa, aparece la hija de Abdo, y el deslinde o la línea de ese Abdo era pasando la represa, y ahí es donde nos hemos juntado a decir por donde van a pasar nuestros deslindes. (Entrevista a socio fundador y productor de "El Rejunte", mayo de 2019).

Posteriormente, también tuvieron conflictos con un vecino del paraje Santa Ana, que comenzó a deslindar hacia adentro del encierro y de límites con el paraje El Puesto. Lo mismo ocurrió con un encargado de uno de los campos aledaños al encierro, quien realizó una exposición policial y posterior denuncia en su contra.

Por su parte, otros campesinos miembros del encierro reflexionan que los episodios de conflicto contribuyeron a que muchos de ellos reconocieran la importancia que tiene la tierra: "si no hay tierra, no hay donde trabajar, donde vivir" (Entrevista a campesina de "El Rejunte", julio 2019). Es decir, la tierra constituye un elemento clave no solo para su sistema productivo, sino para su modo de vida, su cultura e identidad.

En los últimos años, los conflictos por la tierra con los empresarios y quienes alegan la titularidad de dominio se han apaciguado. Sin embargo, la gestión y administración de la posesión y de los recursos allí localizados (ganado y monte) han generado ciertas tensiones entre algunos de los miembros del encierro y 
sobre todo con comunidades vecinas. Las fricciones engendradas estarían asociadas a visiones diferentes y contradictorias sobre los límites del encierro, el uso de los recursos, el uso o no uso de las normas, etc.

Por otro lado, cabe resaltar que algunas familias de la zona reproducen ciertos relatos e historias orales, entre ellos, traen a la memoria el recuerdo de sus abuelos que trabajaron en los obrajes en décadas pasadas y que esas tierras habrían pertenecido o pertenecerían a un tal "Abdo", quien sería el titular registral de las mismas.

La mayoría de nuestros abuelos han sido empleados de los obrajes como ser La Forestal o Weisburd (...). Estaban no solo los ingleses sino también de los árabes y los turcos (muchos aún siguen diciendo que estas tierras son de Abdo) (Entrevista a socio fundador y productor de "El Rejunte", mayo 2019).

Hasta el día de hoy, la cuestión sobre la titularidad de dominio de las tierras no se ha resuelto. Sin embargo, los miembros del encierro avanzan realizando actos posesorios.

Subyace una concepción de propiedad liberal, entendida como entidad o cosa que se tiene. Sin embargo, al analizar todas estas prácticas implicadas en la conformación del encierro, es posible referir a relaciones de apropiación (sociales, políticas, económicas y jurídicas) entre personas respecto a cosas, es decir, no es la titularidad la que define las formas de vida, sino las relaciones que se dan en ese marco. Por lo tanto, en tanto relaciones, no son constantes; cambian, son conflictivas (Montesinos Linares y Campanera Reig, 2017).

En una entrevista con quien es abogado de las familias y comunidades de este y otros encierros, pregunté sobre la transmisión de las tierras en la provincia, y, en particular, por la titularidad de dominio que alegaban y repetían los pobladores de estos parajes. Este profesional del derecho, a partir del estudio de títulos que había realizado con colegas años atrás, respondió:

\begin{abstract}
Siempre hubo robo y apoderamiento. En base a estos estudios que realizamos, encontramos remates fraguados y el sistema de repartijas de las tierras en Santiago. Descubrimos algo terrible; un escribano árabe es el que fraguó los títulos y eso explica lo que sucedió en toda esa zona donde hay quebracho colorado. Esa persona fraguó las ventas a árabes en el Registro de la Propiedad, de campos de personas muertas y del Estado a particulares, ventas inexistentes. (...) Es por eso que vienen con los títulos del pueblo y más allá. Pero estos pobladores siempre han vivido ahí y deben hacer este "cerremos", como una respuesta al problema concreto. (Entrevista a abogado represente de las familias integrantes del encierro "El Rejunte", julio de 2019).
\end{abstract}

La categoría y condición de titularidad de la propiedad de la tierra no solo es privilegiada por los agentes y organismos que agencian el Estado y el derecho moderno, sino que con diferentes matices y contradicciones ha permeado en los propios discursos, memoria y prácticas de los pobladores de "El Rejunte", más allá de que estos se reconocieran como propietarios y privilegiaran la condición del modo o posesión. Asimismo, ello torna inteligible la problemática de inseguridad jurídica en torno a la tenencia precaria de la tierra en la provincia, acentuada en los núcleos donde vive y produce el campesinado.

\title{
Caracterización de la experiencia. La comunidad "El Rejunte"
}

El encierro comunitario ganadero "El Rejunte" se ubica en el departamento Figueroa y agrupa a pobladores de los parajes Santa María, Santa Ana, Santo Domingo y El Puesto, de allí su nombre. El mismo abarca aproximadamente una superficie de 3.000 hectáreas e involucra a 15 familias campesinas. No obstante, cabe destacar que existen diferencias en los diversos relatos de mis entrevistados alrededor de la superficie total del encierro y de las familias que lo integran. Ello no hace más que remarcar las disputas y el proceso inacabado y dinámico en torno a los límites y deslindes del encierro; estos no son asépticos de conflictos, y, por ende, la comunidad se encuentra en permanente redefinición.

Una de las características propias de "El Rejunte" es que las familias y sus viviendas se encuentran adentro del cercamiento, a diferencia de otros encierros en los cuales el alambrado perimetral no incluye las casas o viviendas, debido a la falta de acuerdos entre las familias: 
La diferencia nuestra también con otros grupos es que cuando nosotros hacemos el cerramiento la población queda adentro. En otros grupos el cerramiento queda fuera de las casas porque muchos no están de acuerdo. Aquí están todos de acuerdo, jóvenes, viejos, los abuelos. Nos hemos encerrado y quedamos todos adentro (Entrevista a socio fundador y productor de "El Rejunte", mayo 2019).

Aunque cabe mencionar que hoy en día hay algunas viviendas de familias pertenecientes al encierro por fuera del alambrado perimetral, ya que se fueron sumando a la propuesta con posterioridad.

Desde la perspectiva de los actores involucrados, la composición del encierro en cuanto familias fue variando a lo largo del tiempo, y se ha ido redefiniendo constantemente. Esto lo explican debido a diversos motivos. Algunos miembros se desvincularon por temor a la policía o a futuras acciones judiciales, otros por motivos económicos (por no poner dinero para el alambre, abogado u otras instalaciones). Asimismo, hay quienes se sumaron con el paso de los años.

Los límites (de superficie e integrantes) están en un proceso de redefinición constante. Comprender que la comunidad está en permanente redefinición evita fetichizarla (concebirla como entidad o realidad en sí misma), dado que se considera que son sus prácticas, lo que hacen sus integrantes, lo que va reconfigurándola (Ruiz Ballesteros, 2012). Lo comunitario sería un contexto difuso que depende de su configuración concreta en cada momento y cada lugar. En ese sentido, se tendría que hablar de comunidad como proceso, la comunidad como forma de hacer.

Ruíz Ballesteros (2012) considera que es posible comprender el funcionamiento de una comunidad a partir de las prácticas de sus integrantes, en las formas colectivas de comunicarse, sentir y actuar, de lo que la gente dice y hace. La comunidad entendida como un conjunto articulado de prácticas es inconclusa: las actitudes y acciones no se cristalizan completamente, sino que habitan la tensión entre intereses contrapuestos, lo que constituye un contexto eminentemente contradictorio y dialéctico. Esta doble naturaleza discursiva-práctica de la comunidad marca su realidad dinámica y procesual: la comunidad es tanto relato como acción sin fin (Ruiz Ballesteros, 2012).

Actualmente, las familias, luego de los conflictos que tuvieron, están asesoradas por el profesional a quien entrevisté, y que ha desplegado una estrategia legal-procesal llamada diligenciaspreliminares (previa al proceso judicial), a los fines de consolidar y legitimar ante un oficial de justicia y magistrado los llamados actos posesorios. En esta línea están trabajando en una subdivisión adentro del encierro de unas 700 ha, a su vez subdivida en otras tres, cada una con una represa; una de ellas destinada a la siembra e implantación de pasturas. Asimismo, todo el predio se encuentra rolado y en toda la superficie hay plantines de árboles nativos implantados. Estas y otras actividades se realizaron entre todos los integrantes del encierro, tanto en lo que refiere a los recursos económicos, como al trabajo en conjunto.

Las principales actividades económicas-productivas que se desarrollan son la ganadería caprina y bovina (por el momento cada familia trabaja con sus propios animales) ${ }^{6}$, la apicultura y la extracción forestal para la elaboración de carbón y postes. En este sentido, los miembros del encierro destacan cómo el trabajo con la madera, las vacas y cabras es un oficio que ellos aprendieron vía transmisión generacional, y cómo al mismo tiempo estos saberes les facilitaron la conformación del encierro. En aquella entrevista, el socio fundador de "El Rejunte", quien es hachero y productor de ganado bovino, comenta al respecto:

\footnotetext{
Nuestra diferencia con los otros grupos [se refiere a los otros encierros] es que nosotros nos hemos criado con el hacha en la mano y sabemos lo que es y cómo se debe trabajar la madera, entonces esa ha sido una ventaja para nosotros, que hemos hecho nosotros la madera para alambrar y picar, mucha experiencia en ese trabajo. (...) Pero lo que sí hemos heredado nosotros de nuestros abuelos es la vaca, a nosotros nadie nos ha dicho "ustedes vengan y críen vacas", nosotros nos hemos criado en el medio de las vacas y las cabras, y en ese oficio hemos apuntado nosotros (...). Nosotros tenemos que mejorar muchas cosas, pero siempre en la vaca. (Entrevista a socio fundador y productor de "El Rejunte”, mayo de 2019).
}

El trabajo con el hacha, la madera y la vaca es una disposición ancestral, que se cimenta en prácticas cotidianas de los miembros del encierro, como eje vertebral de sus economías. 
La zona en la que se encuentra constituido "El Rejunte" se caracteriza por la baja disponibilidad de quebrachos colorados (cuya madera es usada para la fabricación de durmientes y postes), por lo que sus integrantes se dedican principalmente a la elaboración de carbón. Por otro lado, al momento tanto de delimitar y cercar las tierras, como de emprender el encierro, este pasado ligado al hacha se convirtió en el eje del trabajo comunal, tanto en la construcción del encierro como en el mantenimiento de los postes y alambres que delimitaban al emprendimiento.

Paralelamente al trabajo forestal, la ganadería constituyó un eje fundamental en la economía de las familias de la zona, es decir, el uso mancomún del monte para el pastoreo y alimentación del rodeo. Algunos estudios en Latinoamérica señalan (Giménez Romero, 1991, citado por Gómez Herrera, Villalba y Tort, 2018) el vínculo entre la actividad forestal y la ganadería, como el desarrollo de comunalidades en áreas rurales, debido a la existencia de ciertas barreras ecológicas, tales como la escasez de agua y la baja aptitud del suelo para el desarrollo de la agricultura.

La ganadería tiene un efecto notable en la comunidad, ya que nuclea lo forestal y lo apícola. Lo pecuario conjuga una diversidad de elementos: la artesanalidad del trabajo (que maximiza el orden de lo simbólico), intensificación del trabajo colectivo y una impronta de defensa por la tierra y los bienes comunes. Constituye un eje fundamental en las economías comunales, debido al carácter especializado de la mano de obra, a un saber-hacer que se transmite de generación en generación. La producción pecuaria tiene un carácter tradicional y artesanal, en el que adquieren importancia los procesos de intensificación de la mano de obra familiar (para efectuar el control del rodeo en las amplias extensiones de tierra por las que se desplaza), con escuetas inversiones, el aprovechamiento de áreas de pastoreo común y las escalas productivas acordes con la disponibilidad de los recursos humanos (Paz, 2018). En otras palabras, la actividad ganadera mancomunada da un sentido de pertenencia y es constituida como uno de los principales estandartes en la lucha por las tierras. Esto se debe a que las inversiones en infraestructura con relación a la producción de ganado bovino son interpretadas como un acto de resistencia ante los posibles avances sobre sus tierras.

Existe un aprovechamiento del capital social existente por parte de los integrantes del encierro al momento de comenzar con esta iniciativa: por un lado, el uso ancestral de la tierra en forma mancomunada para el pastaje de los animales; por otro lado, las prácticas heredadas de la cría de ganado bovino y del obraje. La conformación del encierro les posibilita recuperar disposiciones históricas en torno al trabajo en conjunto alrededor del monte y la tierra. Asimismo, la historia de resistencia y lucha por la tierra y en la tierra de las comunidades ha funcionado como un factor de cohesión grupal que ha contribuido para iniciar la experiencia.

En este sentido, cabe destacar que tanto el cercamiento como las mejoras introducidas a las posesiones se han realizado en gran medida con recursos de los propios socios del encierro, desarrollando capacidad de gestión y administración comunitaria, fijando metas colectivas y desplegando estrategias para alcanzarlas, de tal manera que las condiciones adversas del contexto no los afectaran tanto como, por ejemplo, la disminución o recorte del apoyo económico brindado por las políticas públicas nacionales durante el gobierno nacional de Mauricio Macri. El vínculo de los campesinos con los técnicos y agentes estatales a través del tiempo no ha generado una dependencia externa, en dirección contraria al desarrollo de las capacidades de organización y autogestión. Por otro lado, habrá que considerar en el futuro las asimetrías existentes al interior del encierro entre sus integrantes y familias, en cuanto a la dotación de los recursos pecuarios y el manejo diferencial del monte, los problemas y posibles soluciones que estas situaciones generen.

Si retomamos la entrevista con el socio fundador, observamos que este con posterioridad continúa resaltando las dificultades y obstáculos respecto de la conformación del encierro (algunas de su propia percepción y otras provenientes de vecinos):

Lo único que ha sido costoso y ha durado años ha sido concientizarlos, porque muchos han sido empleados del obraje y tienen un recuerdo de respeto del patrón y del obraje. Al principio se nos reían las familias que han quedado afuera diciendo 
“estos están locos; semejante inversión si cuando venga el empresario compra todo y no sirve nada del trabajo". (Entrevista a socio fundador y productor de "El Rejunte", mayo de 2019).

Estos relatos en torno al hacha y cría de ganado bovino permiten tornar inteligible el hecho de que hay una trayectoria biográfica signada por el trabajo en estos rubros: lo estructural subjetivo, la estructura trasformada en cuerpo a lo largo de la historia, el habitus (Bourdieu, 2007). Los miembros del encierro son plenamente conscientes de las fortalezas y debilidades de sus acciones y estrategias, pero marcan con ellas un horizonte que funda lo comunitario a contracorriente (en algunos aspectos) de las pautas del mercado, del Estado y del derecho oficial.

Estos argumentos de los pobladores se conectan con la visión de los técnicos de terreno en torno a la viabilidad del encierro ganadero a partir de la premisa de intervención y mejora de la producción. En cuanto al aspecto productivo, quien fuera coordinador del equipo técnico de terreno en Figueroa norte del ex PSA expresa:

Lo que deben apuntar es mejorar los índices de producción desde la potencialidad de la comunidad, desde los propios recursos locales, que te permitan como comunidad seguir creciendo y ofrecer nuevas oportunidades a las generaciones futuras. Hay un proceso de aprendizaje sobre lo que se va haciendo y hay distintos avances. El sueño del pibe de estos encierros es tener agua y comida suficientes. Si tengo eso, se mejoran los rodeos, y si se mejoran los rodeos, esto te permite a vos reemplazar la actividad extractiva, que es lo que más retorno da. Yo me acuerdo cuando hablaba con uno de los pobladores; él me decía que aquí, que Santo Domingo era "la industria del carbón" y hoy esos ingresos no están. Entonces nosotros creemos que lo que puede reemplazar esos ingresos es la ganadería (...).(Entrevista a ténico en terreno del PSA, marzo 2019).

Los técnicos de terreno señalan que el diseño del encierro comunitario fue una propuesta técnica gestada en función de los conocimientos ancestrales de los pobladores. Tanto los campesinos como los técnicos coinciden en que no solo se ha avanzado en consolidar la posesión de la tierra, sino también en resolver otros problemas como el robo de la hacienda, dado que con los cercamientos de las superficies de monte y áreas comunes facilitan un control más eficiente del ganado. Asimismo, se ha avanzado en prevenir la degradación de los recursos limitados del monte y suelo. De todos modos, esta experiencia se encuentra en curso y en proceso de consolidación. Hasta el momento no se ha realizado una evaluación (interna o externa) de esta, capaz de arrojar algunos indicadores cuantitativos en cuanto las mejoras productivas alcanzadas y los cambios observables en los sistemas productivos de sus integrantes.

\section{“Haciendo Posesión” desde el encierro comunitario "El Rejunte"}

Por otro lado, entre los fundamentos o razones de la opción por construir un encierro comunitario ganadero, la categoría nativa "hacer posesión" aparece de manera reiterada en las entrevistas con técnicos y exfuncionarios de la SAF, de aquellas realizadas con los pobladores rurales del encierro "El Rejunte", como de otras experiencias análogas del departamento Figueroa, y de los diálogos entablados con miembros de distintas organizaciones campesinas de la zona. En torno a esta expresión, algunos interlocutores se congregaban y se enfrentaban con otros, expresan discrepancias, diferencias y articulaciones de sentidos, racionalidades, y de prácticas (legales, estatales, productivas, culturales y políticas), agenciadas por estos y generadoras al mismo tiempo de sociabilidades y subjetividades.

El nacimiento del encierro ganadero aparece asociado a la idea de producir actos posesorios. En ese diálogo con el socio fundador e impulsor del encierro comunitario "El Rejunte", el mismo expresa:

Nosotros como representantes de nuestras comunidades en la DUFINOC veíamos lo que dice T. [técnico de terreno del PSA], hay que trabajar en las bases y no ir a reunirnos tanto que nos vamos en el palabrerío, los actos posesorios, el trabajo conjunto nos servía mucho más. (Entrevista a socio fundador y productor de “El Rejunte”, mayo de 2019).

En esa misma conversación, este técnico de terreno del PSA en Figueroa, quien fue el coordinador del equipo técnico en este departamento, originario de un paraje vecino y miembro de otro encierro, señala: 
La verdad que siempre hemos tenido diferencias e idas y vueltas con las políticas provinciales para el tema de la tierra, por momento sentíamos que si avanzábamos en lo legal, perdíamos en lo productivo, porque desatendíamos nuestras comunidades. Nosotros ahí hemos decidido que ir a las reuniones provinciales, era perder el tiempo, la gran pelea quepodemos dar nosotros es aqui en el terreno y eso nos ha puesto en relación con otras comunidades similares; nos ha puesto en una posición más sólida, eso ha sido una acertada (...).(Entrevista a ténico en terreno del PSA, marzo 2019).

En esta parte de su exposición se torna inteligible la crítica que realiza tanto a las políticas públicas de tierra provinciales como a los sectores y grupos que han adherido a las mismas, y que adoptaron otras maniobras de lucha.

Posteriormente, en igual dirección habla sobre las miradas divergentes dentro del movimiento campesino en la provincia en cuanto a los modos y estrategias de defensa de tierra:

\begin{abstract}
Había dos debates, que para mi punto de vista nos han retrasado mucho. Una postura era la de decir que el reclamo del campesinado era legítimo, por lo tanto, la ley se tiene que adecuar y no tengo que andar demostrando hasta donde es mi posesión, es la ley la que tiene que venir y reconocer un reclamo que es legítimo; pero la otra corriente era decir "miren muchachos para que\# se va a adecuar la ley si esta\# entongada con los empresarios y lo único que va a buscar es quererte sacar”. Entonces nosotros, si queremos defender la tierra, tenemos que si\# o si\# adecuarnos a lo que dice la ley. La ley dice que vos hoy para reclamar una posesión tienes que tener bien clarito desde dónde y hasta dónde va tu posesión y poder demostrarlo, demostrarlo, no con palabras, sino con hechos que hablen por vos. (Entrevista a ténico en terreno del PSA, marzo 2019).
\end{abstract}

En este sentido, "pelear con la ley", desde la perspectiva de los técnicos de terreno, implica un proceso de legitimación de la propuesta de los encierros ganaderos ante los pobladores rurales, porque con estas iniciativas se busca reafirmar el derecho a la tierra a través del derecho posesorio contemplado en el Código Civil y Comercial de la Nación -por vías institucionales como los programas de desarrollo rural-. Pero también frente a la institucionalidad pública se busca promover la idea de que la limitación de áreas de pastoreo común y los cambios en prácticas tradicionales de manejo de los recursos pecuarios y forestales posibilitaría mejoras en los índices productivos y en los ingresos de los pobladores rurales.

De los dos testimonios, comentados precedentemente, es posible analizar las diferentes sensibilidades legales (Geertz, 1994), es decir, las relaciones que establecen entre los hechos y la ley. Los comentarios expresados por ambos interlocutores en torno a las disputas sobre el derecho posesorio echaron luz sobre la posesión como hecho legal creado socialmente, al igual que la producción de los actos posesorios. Es decir, hacen referencia a la legalidad del derecho posesorio, a la producción legal de la posesión, para justificar por qué introducen mejoras, por qué cierran, cercan y alambran las tierras que compartían de larga data a campo abierto, sobre todo cuando se encontraban en medio de algún conflicto de tierras, o bien preveían la ocurrencia uno; para explicar el porqué de construir un encierro comunitario.

El técnico de terreno del PSA, al mencionar que era necesario "demostrarlo con hechos que hablen por vos", y el productor socio de "El Rejunte", al señalar que lo verdaderamente útil son los "actos posesorios" y el "trabajo en conjunto", aluden a que la producción de "la posesión" como hecho legal empieza antes de la instancia judicial de los conflictos, a través de la producción de actos posesorios, como la delimitación y cercamiento del campo, la construcción de aguadas, represas, la siembra de pastos, la puesta en valor productivo del predio (Gómez Herrera, 2019); actos que podrían ser (re)presentados y juzgados en una futura instancia judicial -bajo los cánones aplicados por los profesionales del derecho- como pruebas del ostensible ejercicio de la posesión. "Hacer posesión" es la categoría utilizada para mencionar y agrupar esas acciones y sus consecuencias.

Por otro lado, de estas manifestaciones, en particular de la del técnico en terreno, se desprende que, si bien en estas experiencias se hace un uso del derecho estatal de posesión y de la prescripción adquisitiva como estrategia de defensa de ellos y las organizaciones que representan sus intereses, no existe un consenso acerca del contenido, las maneras de agenciarlo y de practicarlo. Los distintos posicionamientos en diálogo y disputa sobre la defensa de la tierra referenciados por los interlocutores expresaban las diferentes sensibilidades legales en torno a la posesión (Geertz, 1994). 
Que el técnico exprese que dentro del movimiento campesino hay dos posturas -la primera en la cual "la ley se tiene que adecuar" a las demandas campesinas, es decir, "es la ley la que tiene que venir y reconocer un reclamo que es legítimo", y la segunda, que son ellos los que tienen que "adecuarse a lo que dice la ley"esboza que hay distintos posicionamientos respecto al derecho estatal oficial, lo que implica el despliegue de diversos discursos y prácticas en torno a este, y, por ende, diferentes sensibilidades legales en relación al derecho posesorio. Una de ellas descarta su uso, en tanto su reclamo es legítimo y su derecho no se enmarca o es anterior a la constitución del Estado y del derecho moderno, y la otra hace un uso alternativo de las normas vigentes para hacer efectivo el ejercicio sus derechos.

Ambos entrevistados adhieren a los principios esbozados en las normas contenidas en el Código Civil y Comercial de la Nación, tomando un posicionamiento al respecto. Al decir del pequeño productor de "El Rejunte": "Hay que trabajar en las bases y no ir a reunirnos tanto que nos vamos en el palabrerío, los actos posesorios, el trabajo conjunto nos servía mucho más"; como del técnico en terreno, "la gran pelea que podemos dar nosotros es aquí en el terreno (...) tenemos que si\# o si\# adecuarnos a lo que dice la ley (...)”. Están afirmando que su estrategia de lucha y resistencia se basa en el uso de las herramientas e instrumentos legales que el Estado y el ordenamiento legal ofrecen. Tanto en el relato de los integrantes del encierro como en el de los propios técnicos, estas acciones, como las marcas de propiedad y las mejoras introducidas al inmueble, con miras a mejorar la producción ganadera y el aprovechamiento del monte, están orientadas a resguardar la posesión de las amenazas de desalojo.

Se trata de una interpretación y apropiación del derecho estatal oficial, instituido, y que se sintetizaba en la necesidad de "demostrar" con hechos, con el trabajo en el territorio y no con palabras, los llamados actos posesorios. Así lo evidencia el uso ágil que hacen del vocabulario plasmado en esos códigos y empleado por los profesionales y operadores del derecho estatal. Pero, también, el conocimiento de los procedimientos, requisitos y criterios de aplicación y valoración de esas normas, empleados por aquellos que tienen la facultad de juzgar los hechos. Respecto a esto último, el énfasis puesto en la importancia de "hacer actos posesorios", y en especial de delimitar la "posesión" mediante el alambrado de los campos, reside en el conocimiento de su elevada ponderación como medio de prueba, en tanto acto posesorio clave (Gómez Herrera, 2019) en un juicio de prescripción adquisitiva en el que se dirime la titularidad de dominio.

En este sentido, el técnico de terreno del PSA expresó:

Si un oficial de justicia viene y le muestro que tengo tres mil hectáreas de posesión, es demostrar con aguadas y con divisiones, es demostrar que a todas, las tres mil hectáreas las poseés, hay algunas comunidades que han quedado en esa discusión; por ejemplo, tenemos comunidades que nos dicen que son preexistentes al Estado, entonces no quieren aceptar que haya una ley a la cual adecuarse (...). (Entrevista a ténico en terreno del PSA, marzo 2019).

Esta concepción del derecho posesorio, mediada por la apropiación y subjetivación del derecho oficial, choca con la de otros campesinos y organizaciones, como la del MOCASE Vía Campesina, que mantienen la consigna de "no alambrar", precisamente porque consideran que dicha praxis conlleva la ruptura de costumbres y prácticas ancestrales, de una sociabilidad comunitaria regida por lazos de reciprocidad. A partir de estas prácticas y los discursos divergentes, es posible entender cómo ese referencial propio de los proyectos de encierros ganaderos no constituye un conjunto compacto u homogéneo de representaciones de la realidad o visiones de mundo, coherentes entre si\# y perfectamente articuladas. Por lo tanto, tampoco lo son las definiciones e interpretaciones normativas esbozadas e instrumentadas en concomitancia de manera unilateral.

Ello no hace más que remarcar que las prácticas y discursos de cada actor interviniente en estos conflictos y experiencias están mediados por el tejido de relaciones con otras trayectorias sociales y pertenencias institucionales diversas, como de los contextos en el que se desenvuelven, y el posicionamiento que cada uno ocupa en ellos (Gómez Herrera, 2019).

En esa línea remarco los límites en la plasticidad de los usos del derecho estatal, en el sentido de que no todos los grupos y personas tienen las mismas posibilidades, capitales y poder, al momento de hacer un uso de 
las normas oficiales. Ante ello se vuelve relevante considerar las diferentes identidades sociales de cada uno de los interlocutores, para comprender cómo la definición de la inseguridad jurídica en la tenencia de la tierra como problema y las soluciones operadas en torno a él están mediadas por las nociones y procedimientos de los universos sociales en los que circulaban.

Ambos interlocutores expresan sus posicionamientos en un momento determinado, en tanto producto de su trayectoria personal y profesional, signadas por su tránsito, pertenencia y circulación por instancias, instrumentos e instituciones estatales, lo que obliga a presumir que, en razón de ello, los mismos estuviesen inclinados a ponderar el uso de dispositivos jurídicos y gubernamentales por sobre otras estrategias en la lucha por la tierra, sin por ello caer en la idea de que la iniciativa de alambrar tierras de uso compartido por campesinos sea un mecanismo de cooptación por parte de agencias estatales. Más bien campesinos y agentes estatales se relacionan en la búsqueda de legitimar su accionar de manera complementaria y en ciertas ocasiones contradictorias. Las interpenetraciones de prácticas, nociones y sentidos de derecho, como también lógicas institucionales entre agencias e instituciones estatales y campesinas en la producción de la posesión, posibilita la constatación de la interdependencia y la mutua, ambigua y contradictoria reproduccio\#n de lo estatal y "lo campesino" (Gómez Herrera, 2019).

En este sentido, se torna inteligible otro de los límites en los usos del derecho, el cual se vincula con la internalización de las formas dominantes o hegemónicas de representación del derecho en la propia conformación de la subjetividad, en tanto que, lejos de ser un factor externo, constituyen parte de las experiencias y han pasado a formar parte del sentido común de los grupos dominados (Nader, 1994). Esta última observación sugiere poner la lente sobre los efectos del poder, en particular del ejercicio del poder estatal en la producción de subjetividades y sociabilidades comunitarias en las poblaciones rurales, a partir de la formulación e implementación de las políticas estatales (Gómez Herrera, 2019). Ello no implica que en estos procesos no se jueguen constantemente dinámicas de imposición y resistencia, y que el rol de estos grupos en la creación de imágenes y disputas de sentidos del derecho forme parte activa de estos procesos de emergencia.

$\mathrm{Al}$ adoptar el lenguaje del derecho del Estado nación, los campesinos pueden situar la defensa de la tierra en una escala que resulta la condición para que sus demandas tengan lugar. No se trata solo de que los campesinos han adaptado su accionar a las normas jurídicas estatuidas, sino que sus comportamientos cotidianos se han dotado de contenido jurídico. Así "posesión”, "actos posesorios" y "ánimo de dueño" adquieren sentido a partir de un discurso del derecho que apela a una escala de regulación local donde la descripción detallada y viva de comportamientos, actitudes, nociones, prácticas (cercamiento, implantación de pasturas, construcción de instalaciones, mejoras de infraestructura en los predios, cultivos, etc.) permiten visibilizarlas alrededor de los proyectos de encierros comunitarios ganaderos.

Es a partir de la lógica normativa estatal que los campesinos organizados alrededor del encierro ganadero van dotando de significado y contenido a la "posesión” y a la fórmula "ánimo de dueño". De la misma manera, apelan a una simbolización jurídica de la realidad donde los alambrados o la reivindicación del carácter productivo de sus predios remiten a una preocupación por integrar "las discontinuidades de la interacción social y jurídica en los contextos complejos en que ocurren y en describirlas en términos figurativos y concretos a través de señales icónicas, emotivas y expresivas" (Santos; 2009, p. 247).

En otras palabras, adecuarse a las normas jurídicas de las prescripciones adquisitivas del Código Civil y Comercial y del derecho de propiedad de la Constitución Nacional aumenta las probabilidades de ganar el caso en un futuro. Aunque, se marca la diferencia entre la definición legal del hecho propuesta por los campesinos y aquella requerida en el campo jurídico, el cual de algún modo constriñe el rango de acciones posibles (productivas, organizativas, sociales), y, por ende, limita el dominio de soluciones específicamente jurídicas.

El recurrente uso del lenguaje del derecho oficial les ha permitido la construcción de la demanda del derecho a la tierra como legítima, a partir de la instrumentación de las normas del Estado en su favor, más 
allá del ámbito jurídico estatal, para enfrentar y resistir a los desalojos, aunque reconocieran que la ley esta\# "entongada" con los intereses de quienes los impulsan. Esto, a fin de cuentas, no hace más que afirmar su posicionamiento de que se trata de "luchar con la ley, no con las manos" (palabras del técnico de terreno, PSA). La ley y el derecho, en un sentido más amplio, aparecen en estos casos no solo como instrumento de dominación, sino también, como un espacio y dispositivo de resistencia. A través de los discursos y prácticas, el derecho posesorio, en tanto norma oficial, es accionada y manipulada para confrontar modos de dominación y, por ende, para lograr la emancipación (Santos, 2009).

En esta línea, Edelman (2016) nos ilustra acerca de un doble movimiento que él denomina vernaculización al revés. Frente aquellos procesos unidireccionales (de arriba a abajo), que consisten en el uso de normas instituidas que hacen los grupos sociales cuando adoptan los estándares oficiales, y los convierten en estándares "vernáculos" en el terreno, existen procesos que, lejos de ser unidireccionales, presentan una dinámica más circular, ya que comprenden un flujo de ideas y reivindicaciones que también son de abajo hacia arriba. De este modo, se produce una adaptación creativa de las normas estatales a nivel local, pero también las voces de los movimientos y organizaciones sociales, y las relaciones entabladas entre campesinos con agentes estatales juegan un papel central en la elaboración de las normas que son adoptadas a nivel estatal y global, es decir, que se tienen en cuenta las formas nativas de entender los derechos (los conceptos "vernáculos").

En efecto, es preciso registrar cómo el derecho estatal es apropiado por cada uno de los grupos o comunidades, lo que actúa como condición de posibilidad, pero al mismo tiempo cómo el derecho estatal es reconstruido a partir de las prácticas y discursos de la gente. Ello, a los fines de identificar las distintas tensiones o acoplamientos que tienen lugar en esos (des)encuentros. La dialéctica se da entre las estructuras sociales objetivas y las incorporadas en un proceso histórico, como la agencia de cada uno de los actores sociales (individuales y colectivos).

En este aspecto no se puede eludir el papel de los mediadores sociales (profesionales del derecho, organizaciones sociales, dirigentes, funcionarios, agentes estatales, etc.) en el proceso de traducción e interconexión de los conceptos y derechos vernáculos, y el derecho de la escala estatal u oficial. En este proceso de mediación, ellos mismos construyen representaciones y significados de los mundos que pretenden conectar. (Nussbaumer y Cowan Ros, 2011). Estos desempeñan un rol clave en la definición, legitimación e implementación de los modos de lucha por la tierra, desde las nociones, visiones y valores que promueven a través de sus intervenciones.

En el obrar y discurso de estos agentes intervinientes en la construcción de los encierros ganaderos queda a la vista el carácter dual del derecho: por un lado, el derecho como condición de existencia social, productor de personas, es decir, como parte integral de la cultura y de procesos sociales más amplios; pero también como producto de la agencia humana, es decir, las personas como creadoras de derechos (Nader, 1998; Gómez Herrera, 2019).

El encierro "El Rejunte" se constituye para prevenir los avances y posibles acciones judiciales sobre sus tierras. La producción ganadera y todo lo que esta conlleva está orientada a consolidar los actos posesorios, y a suplir los ingresos que derivan de la actividad extractiva forestal y la degradación del monte como una de sus consecuencias. La iniciativa de cercar las superficies de tierra y monte de uso común -como la instauración de nuevas prácticas de manejo, aprovechamiento y control de los recursos para potenciar la ganadería, de los pobladores de las comunidades que integran el encierro comunitario- puede ser interpretada como una estrategia de negación al despojo de sus tierras y recursos. Al mismo tiempo, la constitución del encierro ganadero y comunitario ha implicado la recreación del derecho y disposiciones del Código Civil y Comercial.

En resumen, la categoría nativa "hacer posesión", mencionada y agenciada por varios de los entrevistados, ya sean campesinos, técnicos en terreno o funcionarios del ex PSA, hacía referencia a diversas estrategias accionadas (cerramientos, mejoras o desarrollo productivo, organización de los grupos o comunidades, trabajo en los predios, etc.) de defensa de la tierra. Estrategias desplegadas en los márgenes o bordes del derecho estatal oficial, es decir, a través de las cuales las normas, instituciones y las prácticas estatales son 
recreadas, resignificadas y reproducidas mediante otros modos de regulación emergentes de las necesidades de las comunidades, para garantizar su supervivencia social, política y económica.

Por otro lado, a través de los diálogos entablados con diversos pobladores del encierro alrededor de la propiedad de la tierra, observé que todos aludían a que esta les pertenecía, debido al tiempo de residencia, a lo trabajado y construido allí, a los lazos gestados en relación con ella; todos hacían alusión a un "nosotros" en sus diversas respuestas. Es decir, aludían a la construcción de un sentido de pertenencia en torno a las actividades y símbolos con relación a la tierra, a su acceso, uso, gestión y control. Así lo expresó una productora de "El Rejunte": "Nosotros somos los dueños de estas tierras, aquí no importa quién tenga los papeles”. Es decir, sus discursos y prácticas señalan una reivindicación colectiva y comunitaria de sus derechos de propiedad de la tierra. Esto se conecta con la premisa de "agruparse", pensada desde el diseño de los encierros, como con las acciones colectivas y de asociación promovidas por los propios campesinos ante los conflictos suscitados. Visibiliza una vez más la dialéctica entre la planificación y gestión de esta política pública y las prácticas y discursos de los pobladores, quienes en un proceso inacabado y dinámico usan las normas y políticas públicas para luchar por sus derechos.

\section{Consideraciones Finales}

Las experiencias de los encierros comunitarios ganaderos situados en los departamentos Figueroa y Moreno, Santiago del Estero, gestados a través de la relación dialéctica entre campesinos, técnicos de terreno y funcionarios del ex PSA-SAF, dan cuenta de la capacidad de agencia de las comunidades rurales, las cuales buscan alternativas al despojo a partir de la resignificación de marcos normativos, y la refuncionalización de los recursos y propuestas técnico-productivas emanados de los programas estatales. Estas iniciativas resultan del despliegue de estrategias orientadas a establecer cercados materiales y simbólicos del patrimonio común de estas poblaciones rurales. Los encierros comunitarios ganaderos constituyen experiencias socioorganizativas emergentes de lucha por la tierra, que presentan grietas identificables en el marco legal y en las políticas públicas. Operan parcialmente dentro del derecho estatal, en sus límites o márgenes, aunque no exentos de tensiones.

En esta línea, destaqué que el derecho es un constructo social, un producto histórico, que se genera y transforma permanentemente a través de las luchas sociales de determinados sectores. Los derechos se construyen en un proceso inacabado y contingente, se re-forman y re-formulan constantemente en función de las condiciones históricas, las necesidades, los intereses, las luchas y resistencias de ciertos colectivos, los medios disponibles para su realización, etc.

En la actualidad, los campesinos santiagueños nucleados alrededor de los encierros hacen usos alternativos de las normas, de lo disponible, para posicionarse como sujetos políticos en la agenda pública y reclamar en iguales términos a los empleados por el Estado. Esto ocurre a los fines de tener lugar en el lenguaje del Estado y de la ley, y poder así lograr el reconocimiento de sus derechos. Estos sectores recrean y resignifican sus estrategias de resistencia en esa compleja lucha contra el Estado y dentro de él, y han logrado conquistas en ciertos ámbitos públicos. De este modo, las políticas públicas son forjadas día a día por procesos complejos, en los que la acción colectiva de estos sectores intenta instalar el tema (derecho a la tierra) en la agenda política. Son las voluntades extrañadas, disidentes, inconformadas con lo existente, las que inscriben paulatinamente sus aspiraciones y demandas en el discurso de la ley.

Los campesinos partícipes en estas experiencias realizan un uso alternativo de una figura legal como la prescripción adquisitiva, que nació bajo la idea de protección y legitimación de la "posesión" de los grandes terratenientes de la Pampa Húmeda, tierras arrebatadas y adquiridas mediante la violencia sobre otras culturas (Caballero de Aguiar y Ghersi, 2006). Así, a través de la mediación con diversos agentes estatales introducen mejoras, producen, se organizan y paradojalmente cercan los históricos campos comunitarios abiertos para frenar los intentos de desalojo. En este sentido, se torna inteligible cómo los instrumentos y 
figuras legales funcionan de diversas maneras, conforme a los usos que de ellos se hagan. Es decir, cómo el derecho puede operar como un dispositivo de gobierno de las relaciones sociales (Sierra y Chenaut, 2002), que posibilita jerarquizar, categorizar, clasificar, y ordenar, pero también resistir, resignificarse, transformar y emancipar.

No obstante, analicé que estos usos alternativos del derecho no poseen una plasticidad ilimitada. La cualidad maleable de los usos encuentra uno de sus límites al constatar que no todos los grupos se enfrentan con las mismas experiencias, pues las interpretan bajo circunstancias que ellos no han elegido; no todos tienen el mismo poder o posición relativa para definir los sentidos del derecho. En este sentido, traté de visibilizar, a través del "El Rejunte", que sus potencialidades de invención o construcción han sido distintas, desiguales con respecto a otros encierros, en particular por las identidades yuxtapuestas y permeadas por la vinculación y circulación de sus miembros por instituciones estales, lo que implicó que consideraran como oportuno el uso de los instrumentos jurídicos, de los programas y políticas públicas ofrecidas por el Estado, por sobre otras estrategias. En este sentido, es necesario resaltar que la producción de legalidades en procesos de disputas, como los conflictos de tierras, son parte de procesos sociales más extensos, parte integral de la cultura (Nader, 1998).

Por otro lado, destaqué cómo algunos de mis interlocutores, en particular aquellos dispuestos a acceder y hacer un uso de lo disponible, realizan una internalización y apropiación de las formas dominantes de representación del derecho en la propia conformación de su subjetividad, en tanto, lejos de ser un factor externo, constituyen parte de las experiencias y han pasado a formar parte de su sentido común, de sus discursos y prácticas cotidianas (Nader,1994). Es decir, el derecho se revela como expresión de la correlación de fuerzas en la sociedad, desde la relación derecho-poder, si se considera el doble significado del Estado como orden político institucionalizado y como condición de existencia (Sierra y Chenaut, 2002).

De hecho, el hecho de que muchos se autoidentifiquen como "poseesores", "co-poseedores" u "ocupantes con ánimo de dueños” implica la apropiación de las categorías del derecho oficial, de su retórica. Asimismo, que decidan introducir valor económico a sus predios o alambrar aquello que históricamente han usado sin límite alguno conlleva un conocimiento de que estos hechos tienen una elevada ponderación como prueba en un juicio de prescripción adquisitiva. Es decir, adquieren un valor central para aquellos facultados a decidir los hechos e interpretar las normas, que son quienes, a fin de cuentas, constriñen de algún modo los contenidos y formas de los reclamos, si se pretende obtener un juicio con sentencia declarativa de dominio favorable. El derecho estatal funciona o es empleado como instrumento político para disputar ciertos espacios y a la vez hacer ciertos reclamos de justicia. Su utilización implica un proceso complejo, ambiguo e inacabado de circularidad en las transformaciones mutuas.

En esta línea, el estudio del encierro ganadero permitió tornar inteligibles las distintas sensibilidades legales, con relación al derecho de propiedad y la posesión de las tierras. Es decir, hizo visible cómo los distintos actores involucrados re-significan los objetivos originales de un programa, de una política pública nacional, que había surgido con un perfil primordialmente económico-productivo, a los fines de consolidar y legitimar la posesión de estas comunidades.

A través del diálogo entablado con los distintos interlocutores pude identificar una resignificación de los preceptos jurídicos del Código Civil y Comercial de la República Argentina, por medio de las diferentes expresiones, prácticas y contenidos con que dotaban a los actos posesorios al "hacer posesión". Es decir, cómo agencian esta figura legal en torno a los usos que realizan de las normas y de una política pública. Para las familias campesinas partícipes del encierro "El Rejunte”, "posesión” adquiere sentido a partir de un discurso del derecho que apela a una escala de regulación local, según la cual el derecho a la tierra se basa en usos, costumbres y prácticas socioproductivas, organizativas y estatales que remiten a una apropiación comunitaria de la tierra; proceso no exento de contradicciones. Pensar las sensibilidades legales (Geertz, 1994) y las relaciones entre hechos y ley en el marco de "El Rejunte" lleva a destacar que los campesinos entablan relaciones multidimensionales con la tierra. Estos se ajustan al "modo" o posesión requerido por 
el derecho oficial como requisito constitutivo del derecho de propiedad, pero, al mismo tiempo, operan por sobre lo que dice la ley, que agrega el título, el cual en última instancia termina privilegiado en los ámbitos jurídicos institucionales.

\section{REFERENCIAS}

Bourdieu, P. (2007). El sentido práctico. Buenos Aires: Siglo XXI Editores.

Caballero de Aguiar, M. R., y Ghersi, C. (2006). La prescripción liberatoria y adquisitiva civil-comercial-penal. Buenos Aires: Cathedra Jurídica.

de Dios, R. y Ferreyra, R. (2011). La defensa de la tierra y la experiencia de los encierros ganadero de manejo comunitario en Santiago del Estero. En R. Paz y R. de Dios (comp.), Actores sociales y Espacios protegidos. Aprendizajes de experiencias rurales en el NOA (pp. 63-92). San Miguel de Tucumán, Argentina: Magna Ediciones.

Edelman, M. (2016). Estudios agrarios críticos: tierras, semillas, soberania alimentaria y derechos de las y los campesinos. Quito: Editorial IAEN.

Geertz, C. (1994). Conocimiento local. Buenos Aires: Paidós.

Gómez Herrera, A. (2019). "Hacer posesión”. Dispositivos y prácticas de gobierno de lo común en una población rural de Santiago del Estero, Argentina. RevIISE - Revista De Ciencias Sociales Y Humanas, 14(14), 135-146.

Gómez Herrera, A., Villalba, A., y Tort, J. (2018). Comunalidades en el espacio rural, una mirada desde las prácticas. Experiencias de encierros comunitarios y ganaderos en Santiago del Estero. En R. Paz, R. Rodriguez Sperat y C. Jara (comp.), Sistemas comunales y explotaciones si limites definidos. Persistencias del campesinado en la Argentina (pp. 181-232). Santiago del Estero: EDUNSE.

Montesinos Linares, L., y Mireia Campanera, R. (2017). Formas de vida, usos y apropiación de recursos. Propuestas para el estudio de los comunes contemporáneos. Revista de Antropologi\#a Social, 26(2), 193-216.

Nader, L. (1994). Harmonia Coercitiva: a economía política dos modelos jurídicos. Revista Brasileira de Ciências Sociais, 29, 19-29.

Nussbaumer, B., y Cowan Ros, C. (2011). Trayectoria conceptual de la mediación social: expedicionarios, patrones, políticos y profesionales técnicos en la interconexión y producción de mundos de significados. En B. Nussbaumer y C. Cowan Ros (ed.), Mediadores sociales. En la producción de prácticas y sentidos de la politicapública (pp. 17-68). Buenos Aires: CICCUS.

Paz, R. (2018). Estructura agraria, explotaciones sin límites definidos y matrices comunales: miradas alternativas, dilemas y disyuntivas. En R. Paz, R. Rodriguez Sperat y C. Jara (comp.), Sistemas comunales y explotaciones si límites definidos. Persistencias del campesinado en la Argentina (pp. 23-62). Santiago del Estero, Argentina: EDUNSE.

Ruiz Ballesteros, E. (2012). La vigencia de la comunidad. Prácticas para navegar en la globalización desde la periferia andina. Chungara, Revista de Antropología Chilena, 44(3), 419-433.

Santos, B. de S. (2009). Sociología Jurídica Crítica. Para un nuevo sentido común en el derecho. Bogotá: Editorial Trotta/ Ilsa.

Sierra, M. T. y Chenaut, V. (2002). Los debates recientes y actuales en la Antropología Jurídica: Las corrientes anglosajonas. En E. Krotz (Ed.), Antropología jurídica: perspectivas socioculturales en el estudio del derecho (pp. 113-170). Ciudad de México: Universidad Autónoma Metropolitana.

Villalba, A., Gómez Herrera, A., Concha Merlo, P., y Ferreira, R. (2016). Procesos de producción y apropiación de novedades socio-productivas en el manejo del monte y el ganado. Experiencias de Encierros Comunitarios Ganaderos en el Noreste de Santiago del Estero. En M. Gutiérrez y V. González (comps.), Desarrollo Rural y Política Pública y Agricultura Familiar (pp. 69-87). San Miguel de Tucumán, Argentina: Magma Publicaciones. 


\section{Notas}

1 Esta organización de segundo grado surgió en la década del ochenta. Se encuentra integrada por organizaciones de base campesinas de once comunidades del norte del departamento Figueroa. Tiene su sede en Bandera Bajada (Figueroa).

2 La Mesa de Tierras de Figueroa surge en el año 2003, en el contexto de conflictos por la tierra y está conformada por delegados de distintas comunidades de Figueroa y Moreno. Su sede está situada en Bandera Bajada; recibía apoyo de la ONG internacional ISCOS, destinado a la asesoría jurídica de campesinos afectados por problemáticas como: tenencia de la tierra, acceso al agua, preservación del monte, etc. (De Dios y Ferreyra, 2011).

3 Las cursivas a lo largo de todo el texto son propias.

4 Actualmente carecen de apoyos financieros por parte de organismos nacionales y provinciales. Aunque destacan el acompañamiento, fundamentalmente en cuanto capacitación técnica, de un ingeniero agrónomo del INTA (Instituto Nacional de Tecnología Agropecuaria), quien tomo contacto con ellos a través del Programa "Manejo de Bosque con Ganadería Integrada” (MBGI).

5 Criterio de elegibilidad establecido por el PSA para ser beneficiario de esta política pública.

6 En "El Rejunte" convive un universo marcado por la posesión comunal del territorio y de todos sus recursos, con otros individualistas. Por tanto, la construcción de la comunidad depende de la articulación de los intereses y compromisos colectivos, con los deseos y expectativas individuales. (Ruiz Ballesteros, 2012). 